Research Article

\title{
Research on Price Wars in Supply Chain Networks Based on Multistage Evolutionary Prisoner's Dilemma Game
}

\author{
Xiangbin Xu $(\mathbb{D}$ and Ermin Zhou $(\mathbb{D}$ \\ School of Traffic and Logistics, East China Jiaotong University, Nanchang, Jiangxi 330013, China \\ Correspondence should be addressed to Xiangbin Xu; 735081424@qq.com
}

Received 22 May 2019; Accepted 3 October 2019; Published 11 November 2019

Academic Editor: Sitek Paweł

Copyright (C) 2019 Xiangbin Xu and Ermin Zhou. This is an open access article distributed under the Creative Commons Attribution License, which permits unrestricted use, distribution, and reproduction in any medium, provided the original work is properly cited.

\begin{abstract}
In this paper, we extend price wars to supply chain networks (SCNs), focusing on how price wars affect the performance of SCNs and how to contain a price war. We propose a computational model in which the price competition is modelled as a multistage evolutionary prisoner's dilemma game between business-related neighbors in each stage of the SCN, and the temptation to defect of the prisoner's dilemma game is modelled as a function of the quotation price, which couples the price competition and the dynamic of the SCN. It is found that the price defectors' exposure rate is the key factor causing price war of the SCN, and only a large proportion of firms in a closely related industry join the price alliance, and the price war in the SCN can be contained effectively.
\end{abstract}

\section{Introduction}

In order to fight for customers and market shares, cooperation and competition are common practices among firms in SCNs, and price competition is the most commonly used means of market competition [1-3]. The expansion and extension of price competition often lead to repeated cutting of prices among competitors; one competitor lowers its price, then others lower their prices to match, which eventually results in a price war. Price wars commonly start with one firm trying to take hold of the market share [4] and are marked by competing firms struggling to undercut each other [5]. Many industries have suffered from damage resulting from price wars in recent years [6-8]. China's most famous price war broke out recently in the online home appliance industry, triggered by the malicious price markdown of China's two leading online home appliance retailers, 360 Buy and Suning [9]. Price wars have five typical characteristics [10]: first, they mainly involve most firms in the whole industry; second, the direction of the pricing is downward; third, no firm wants to start a price war deliberately; fourth, the pricing interplay is undesirable and the pricing behavior is against business norms; and fifth, the pricing interaction becomes fiercer as the price war deepens. Price wars greatly reduce the industry's profits, lower the whole industry's efficiency, worsen the competitive environment, and can even destroy the entire supply chain. Regarding the measures to counter price wars, forming a price alliance [11] is the most common practice. To avoid vicious competition, firms in a price alliance cooperate and sign a fixed price contract or set a minimum protection price agreement. A good case of a price alliance is China's nine top TV giants' announcement of a minimum selling price for colour TVs at the Chinese TV Summit 2000 held in Shenzhen [12].

The purpose of a price alliance is to boycott individual firms' malicious price speculation. From the game theory point of view, the formation and expansion of a price alliance are the results of price gaming among firms in the same industry [13]. Evolutionary game theory is the application of game theory to evolving populations of life in biology, focusing on how the players with bounded rationality maximize their pay-off by changing their strategy dynamically as the populations evolve. As a powerful tool for studying players' cooperative behavior, evolutionary game theory is widely 
used in the economics and management research areas [14-16]. In particular, the prisoner's dilemma game (PDG) has become a general paradigm for studying the cooperative behavior between bounded rational players in an evolutionary game, and the evolution of cooperation in different network models, such as lattices [17-20], small-world [2123], and scale-free [24-26], has been intensively studied. In the original PDG, two players are pure strategists and simultaneously decide whether to cooperate (C) or defect (D). The defector will always have the highest reward PT (temptation to defect) when playing against the cooperator who will receive the lowest pay-off PS (sucker value). If both players cooperate, they will receive a pay-off $P R$ (reward for cooperation), and if both players defect, they will receive a pay-off $\mathrm{PP}$ (punishment). Moreover, these four payoffs satisfy the following inequalities: $\mathrm{PT}>\mathrm{PR}>\mathrm{PP}>\mathrm{PS}$ and $\mathrm{PT}+\mathrm{PS}<2 \mathrm{PR}$. According to classical game theory, the dominant strategy in a single-round PDG is that both players choose to defect, but mutual cooperation results in a higher pay-off for players in an evolutionary PDG. Therefore, this situation creates a social dilemma. Porter [27] and Green [28] were among the first to model a price war as repeated PDGs and assumed that the firms were noncooperative which would revert to cooperative pricing after a predetermined finite number of periods. Paul et al. [29] considered the reverse situation in which firms intend to behave in a cooperative manner, but periods of noncooperative behavior may arise; firms were assumed to use a "tit-for-tat" strategy, and they found that price wars can occur periodically in an industry even when all the firms behave cooperatively and each firm has no intention of "cheating" by attempting to undercut the other firms. Dunne [30] also used repeated PDGs to show that price wars are destructive and unprofitable but avoidable. However, their research works only involved the price wars in a single industry.

It is well known that an SCN is a multistage, heterogeneous network constituted by many firms [31-34]; differing from other kinds of network, the complexity of an SCN lies in the interplay and coevolution among the network structure, the network strategy, and the network dynamics [35-37]. The cooperation and competition between the price alliance and the price war is a typical network strategy of an SCN, which also has a direct impact on the evolution of the dynamic of the SCN, meaning that the behavior and features of a price war in an SCN become more complicated in comparison within one single industry. Moreover, a price war in an SCN encompasses not only the competing firms but also all the entities, such as suppliers, distributors, retailers, and customers, so a price war in an SCN can affect almost every firm within it, and its destruction can be more severe than in a single industry. How does a price war affect the performance of the whole SCN? Can a price alliance always contain a price war effectively in an SCN? What are the key factors that affect the competition between firms in a price alliance and those in a price war? Exploring these issues can provide us with a clear understanding of the behavior and features of price wars in SCNs and help us take effective measures to prevent SCNs from suffering damage caused by price wars.
To the best of our knowledge, so far, many previous works on price wars have been based on only one single industry and only price competition has been explored. However, SCNs include many closely interrelated industries and a price war in one industry can easily spread through the SCN. Therefore, in this paper, we extend price wars into SCNs and focus on how a price war affects the performance of the SCN and how to contain a price war in the SCN. We construct a model that integrates the price competition and dynamic of the SCN, in which the price competition is modelled as a multistage evolutionary PDG and is coupled with the dynamics of the SCN by mapping the price markdown into the temptation to defect of the PDG. The simulation results show that the malicious price defectors' exposure rate has a decisive influence on the performance of the SCN, and the business connectivity of the SCN and the size of the price alliance have a direct impact on the price alliance's capability of containing the price war. The remainder of this paper is organized as follows. In Section 2, the model is introduced in detail. Section 3 presents the simulation results and discussions. We finally draw conclusions in Section 4.

\section{Model}

2.1. SCN Model. We consider an SCN consisting of $N$ nodes and $K$ stages (Figure 1 ). The stages of the SCN are numbered in the direction from consumers $(k=1)$ to manufacturers $(k=K)$. The nodes in different stages play different roles in the SCN: the nodes in the first stage $(k=1)$ represent the consumers, whereas the nodes in the last stage $(k=K)$ represent the manufacturers and the nodes in the stage between consumers and manufacturers (from $k=2$ to $k=K-1$ ) represent the middlemen, such as retailers, wholesalers, and distributors. Because firms in the same stage (except the first stage) make/sell the same products, they fight for the same customers in the market, so we consider each stage (except the first stage) of the SCN as an industry. The nodes are connected by undirected links. Although an SCN is made up of nodes and links, it is different from other complex networks in the following respects: (1) heterogeneous nodes: the nodes in different stages have different business behaviors, consumers buy and consume products, middlemen distribute, store, and sell products, and manufacturers make products; (2) hierarchical linking: links represent the information flow and product flow in an SCN and they only connect the nodes in two adjacent stages of the SCN, so links between nodes in the same stage are not allowed; (3) nonweighting networks: in our SCN, the links between nodes only mean the business relationship between them, so we do not attach any more business meaning, such as transportation capacity and strength of the business relationship, to them.

In each time step, two opposite flows cross the SCN: orders are first transmitted upstream from the first stage to the last stage and products are then transmitted downstream from the last stage to the first stage. The business processes of consumers, middlemen, and manufacturers are defined as follows. 


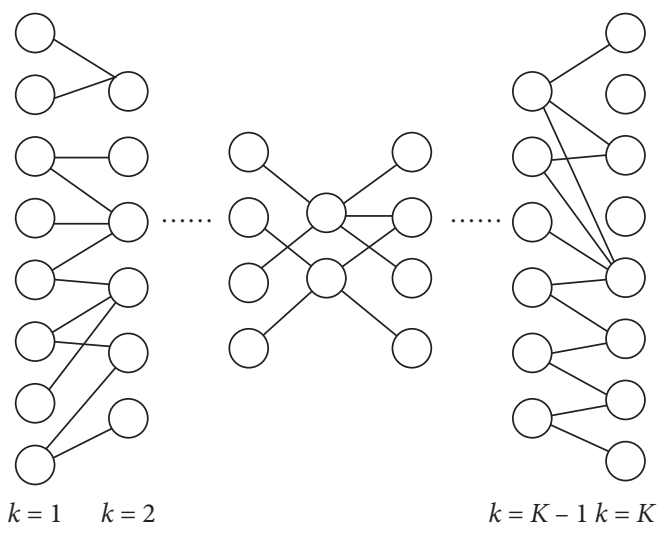

FIGURE 1: The structure of an SCN.

2.1.1. Consumers. Consumers are the source of the demand. In each time step, all consumers decide on the amount of products they will consume in the next time step according to some preset rule, and then they select the supplier from their candidate firms and place orders with them, respectively. Subsequently, consumers receive the products they ordered in the previous time step. We assume that the demand of consumers is exogenous and the products are fully absorbed by the consumers in each time step. The business process of the consumers is shown in Figure 2(a).

2.1.2. Middlemen. Although middlemen include different roles, such as retailers, wholesalers, and distributors, their business processes are similar. The middlemen carry out the same tasks in each time step:

(1) Receive shipments from suppliers and update the available inventory in the current time step

(2) Receive orders from downstream customers sent in the current time step

(3) Send shipments to downstream customers (customers with backlogged orders enjoy high priority for shipments)

(4) Forecast the demand in the next time step and adjust the order size considering the current inventory or backlogged orders

(5) Receive quotations from all the candidate firms sent in the previous time step, then select the supplier and place an order

(6) Play price competition games with their neighbors and send the quotation for the next time step to their potential customers

(7) Calculate their sales revenue and inventory cost and update their total capital

In our model, we do not consider the order transmission delay. Only the one-period delivery delay is considered here, i.e., an order sent in time step $t$ is received by the supplier in the same time step $t$, whereas shipments delivered in time step $t-1$ are received by the customers in time step $t$. We also take the one-period quotation transmission delay into account, i.e., the quotation sent in time step $t-1$ is received by the potential customers in time step $t$; moreover, our model does not consider middlemen's production cost and payment delay, which means that consumers and middlemen pay their suppliers immediately after receiving shipments. The business process of the middlemen is shown in Figure 2(b).

2.1.3. Manufacturers. Manufacturers make products and supply them to the SCN. The manufacturers in our model have unlimited production capacity and make products without delay. In each time step, manufacturers receive orders from downstream customers, make products, and deliver products to their customers. The business process of the manufacturers is shown in Figure 2(c).

It should be mentioned that our model is based on the SCN framework proposed by Weisbuch and Battiston [36], which is a simple but robust SCN model to analyze the dynamic of an SCN. However, we make the framework more realistic by incorporating price competition into the SCN framework. We will discuss the middlemen's three additional behaviors in our model briefly in the following:

(1) Play price competition games with their neighbors

(2) Send quotations to their potential customers

(3) Receive quotations from their candidate firms

In additional behavior 1 , the middleman $i$ in stage $k$ plays $n$-round PDGs with its $n$ neighbors; the different strategies the middleman takes in playing the PDG lead to different quotation prices for its potential customers. In additional behavior 2, the middleman sends quotations to its potential customers, respectively, which will be received by the potential customers in the next time step. In additional behavior 3 , the potential customers receive quotations from the candidate firms and try to select the firm that offers the lowest quotation price as their supplier and places an order. The three additional behaviors in our enhanced model establish a relationship between the quotation price and the PDG's game strategy, so the price competition and dynamic of the SCN are coupled in the same model.

2.2. Dynamic of the SCN. In this paper, we only focus on the middlemen's price cooperation and competition and their impact on the dynamic of the SCN, so we only build the dynamic of firm $i$ located in the $k(1<k<K)$ stage of the SCN.

2.2.1. Receive Shipments. In time step $t$, firm $i$ receives shipments from upstream suppliers; the total products $Y_{i}^{s}(t)$ firm $i$ receives in time step $t$ are the aggregation of the shipments sent by all its suppliers in time step $t-1$ :

$$
Y_{i}^{s}(t)=\sum_{v \in V_{i}} Y_{i, v}^{s}(t-1),
$$

where $V_{i}$ is firm $i$ 's supplier set and $Y_{i, v}^{s}$ is the shipment from firm $i$ 's single supplier $v$, which includes products that firm $i$ ordered in time step $t-1$ plus, if any, products for firm is backlogged order before time step $t-1$. After receiving the shipments, firm $i$ updates its current available inventory $I_{i}(t)$ as 


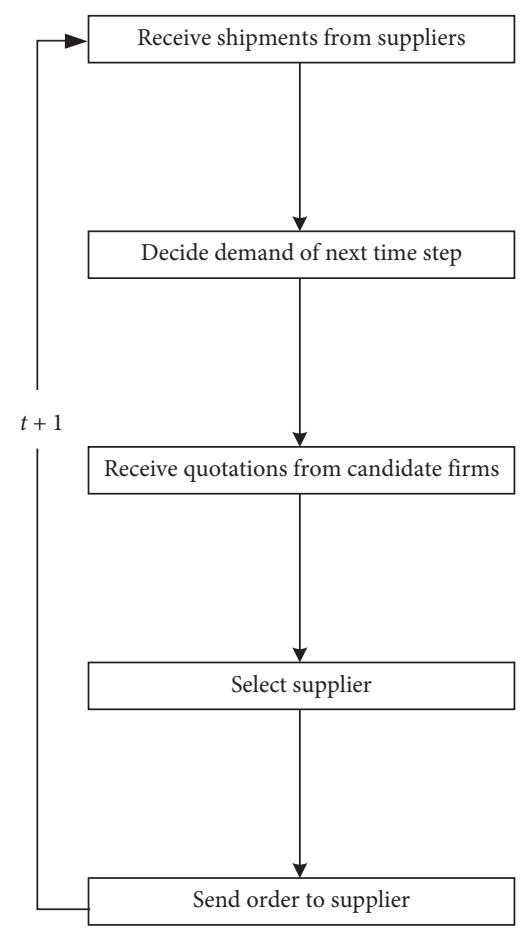

(a)

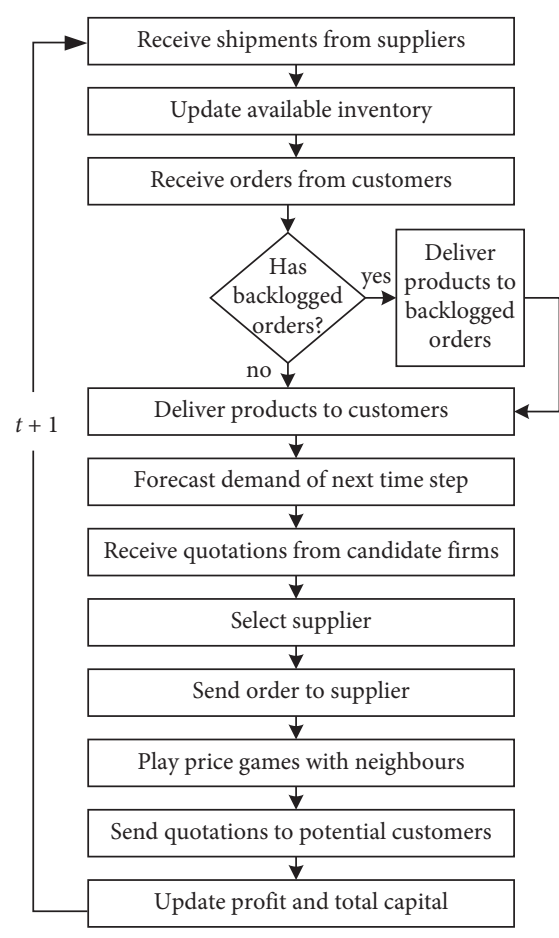

(b)

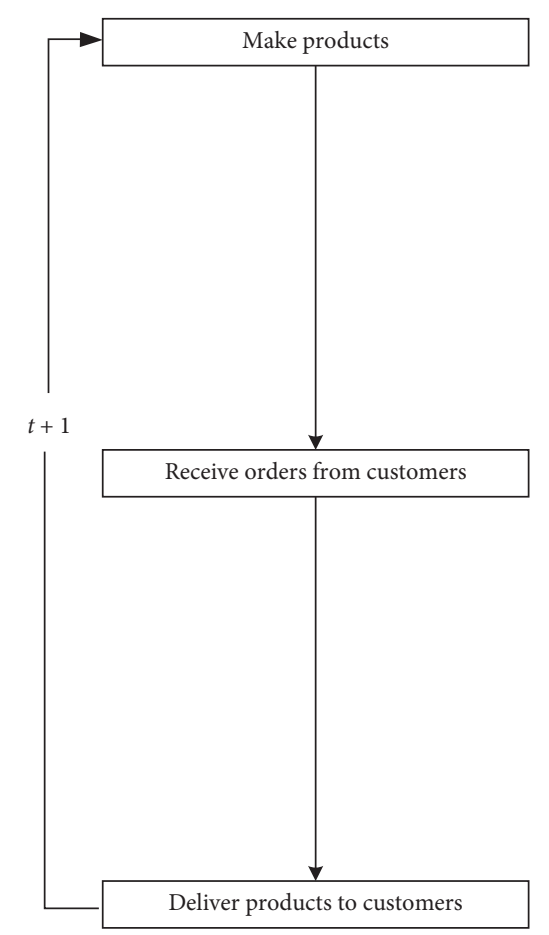

(c)

FIgUre 2: The business process of the nodes in an SCN. (a) The business process of the consumers. (b) The business process of the middlemen. (c) The business process of the manufacturers.

$$
I_{i}(t)=I_{i}(t-1)+Y_{i}^{s}(t)
$$

where $I_{i}(t)$ is firm $i$ 's available inventory in time step $t$.

2.2.2. Receive Orders and Deliver Products. In time step $t$, firm $i$ receives and aggregates orders from downstream customers; the total orders $\Omega_{i}(t)$ that firm $i$ receives in time step $t$ are the aggregation of orders sent by all its customers in time step $t$ as

$$
\Omega_{i}(t)=\sum_{c \in C_{i}} Y_{i, c}^{d}(t)
$$

where $C_{i}$ is firm $i$ 's customer set and $Y_{i, c}^{d}(t)$ is the order from firm $i$ 's single customer $c$. Then, firm $i$ decides on the total available shipments $Y_{i}^{d}(t)$ that it can deliver in the current time step according to the following equation:

$$
Y_{i}^{d}(t)=\min \left(I_{i}(t), \Omega_{i}(t)\right) .
$$

If $I_{i}(t)<\Omega_{i}(t)$, firm $i$ cannot meet all its customers' demand in the current time step, and some customers' orders must be delivered in a later time step; the backlogged orders $B_{i}(t)$ of firm $i$ in time step $t$ are

$$
B_{i}(t)=\Omega_{i}(t)-I_{i}(t) .
$$

If the orders cannot be fully satisfied, firm $i$ distributes its available inventory on a simple first-come-first-served (FCFS) basis, which means that firm $i$ firstly satisfies the backlogged orders received in the previous time step, and then it satisfies the orders received in time step $t$.
2.2.3. Forecast and Order. After delivery, firm $i$ decides whether it needs to order products from its supplier; if an order is necessary, firm $i$ 's order size $O_{i}(t)$ in time step $t$ depends on the demand forecast $F_{i}(t+1)$ of time step $t+1$, the available inventory $I_{i}^{\prime}(t)$ after delivery, or, if any, the backlogged orders $B_{i}(t) . O_{i}(t)$ is calculated as follows:

$O_{i}(t)= \begin{cases}F_{i}(t+1)-I_{i}^{\prime}(t)+B_{i}(t), & \text { if } F_{i}(t+1)-I_{i}^{\prime}(t)+B_{i}(t)>0, \\ 0, & \text { otherwise. }\end{cases}$

If $O_{i}(t)>0$, firm $i$ needs to order products from an upstream supplier. For simplicity, we do not consider an ordering strategy such as fixed order quantity (FOQ) or economic order quantity (EOQ) here. Firm $i$ 's order size in time step $t$ is exactly the same as $O_{i}(t)$; moreover, firm $i$ selects the firm with the lowest quotation price as its supplier from the candidate firms and places an order.

In time step $t$, firm $i$ forecasts its demand in time step with a simple moving average model as

$$
F_{i}(t+1)=\frac{\sum_{t^{\prime}=t-l+1}^{t} O_{i}\left(t^{\prime}\right)}{l},
$$

where $l$ indicates that firm $i$ only takes $l$ latest past actual demand into consideration when it forecasts.

\subsection{Price Competition of the SCN}

2.3.1. Price Alliance's Price. We consider each stage (except the first stage) of an SCN as an industry and that the firms in 
the same industry make/sell the same product. To keep things simple, we model the product's average price of industry $k$ as follows:

$$
P_{k}(t)=P_{K}(t)+K-k,
$$

where $P_{K}(t)$ is the selling price of the manufacturers located in stage $K$ (the last stage) of the SCN. If firm $i$ is a cooperator in a price alliance, the quotation price for its potential customers is around $P_{k}(t)$; to make our model more realistic, we take the firm's operational capability into consideration and we set the single firm is quotation price $P_{i, c}(t)$ for all its individual customers $c$ as the random outcome of a market process around the average price of industry $k P_{k}(t)$. According to the law,

$$
P_{i, c}(t)=P_{k}(t) * u_{i}(t)
$$

where $u_{i}(t)$ is the price fluctuation for the single firm $i$, which is a random variable that is uniformly distributed in $[1-\xi, 1+\xi]$ and is independent of the average industry price $P_{k}(t)$.

2.3.2. Price Defectors' Price. As we mentioned in Section 2.1, in each time step $t$, firms acting as middlemen in the SCN play price-based PDGs with their $n$ neighboring firms in the same stage. Just like the original PDG, the firms in the PDG are pure strategists, following two simple strategies: cooperate $(C)$ and defect $(D)$. If firms $i$ and $j$ are in the same stage $k$ of the SCN and they have common potential customers, we consider their fighting for common potential customers as a price-based PDG. According to Nowak and May [38], the spatial distribution of PDG strategies is described by a two-dimensional unit vector for each firm, namely,

$$
\begin{aligned}
& U=\left(\begin{array}{l}
1 \\
0
\end{array}\right), \\
& U=\left(\begin{array}{l}
0 \\
1
\end{array}\right),
\end{aligned}
$$

for cooperators and defectors, respectively.

Without losing the generic feature of the PDG, the payoff matrix has a rescaled form, suggested by Nowak and May [38]:

$$
W=\left(\begin{array}{ll}
1 & 0 \\
b & 0
\end{array}\right) .
$$

In the rescaled PDG form, mutual cooperators each score 1 , mutual defectors score 0 , and defectors score $b$ against cooperators (who score 0 in such an encounter). The only parameter $b$ characterizes the advantage of defectors over cooperators (defectors will gain more when $b$ is larger), so $b$ is signified as the defectors' temptation to defect in the PDG by Nowak and May [38]. Besides, $1<b<2$, which means that defectors' temptation to defect in the price competition is no larger than the total pay-off received from cooperation.

When firms $i$ and $j$ play a PDG in fighting for customer $c$, and firm $i$ is a price defector, its quotation price $P_{i, c}(t)$ or its individual customer $c$ is modelled as the function of its temptation to defect $b$ :

$$
P_{i, c}(t)=Q_{i}(t)+\left(P_{k}(t)-Q_{i}(t)\right) *(b-1),
$$

where $Q_{i}(t)$ is firm $i$ 's average procurement price in time step $t$ and $P_{k}(t)$, as described in equation (8), is the contracted price agreed by the price alliance in stage $k$.

Equation (12) deserves a further discussion here. In price-based competition environments, firm $i$ clearly knows that its potential customers will buy products from the firm offering the lowest quotation price, so if firm i's quotation price for its individual customer $c$ is slightly lower than the contracted price agreed by the price alliance $P_{k}(t)$ (which corresponds to $b=2$ in equation (12)), firm $i$ can both win customers and guarantee maximum profit, so it has the maximum temptation $(b=2)$ to defect. If firm $i$ sets the quotation price slightly higher than the average procurement price $Q_{i}(t)$, though winning customers undoubtedly, it can hardly gain profits at all, so firm $i$ has the minimum temptation $(b=1)$ to defect. The relation of firm i's quotation price $P_{i, c}(t)$ and its temptation to defect $b$, described in equation (12), is shown in Figure 3.

We can see from equation (12) and Figure 3 that firm $i$ is most likely to defect $(b=2)$ by setting the quotation price slightly lower than the price agreed by the price alliance $P_{k}(t)\left(P_{\mathrm{C}_{1}}\right.$ in Figure 3$)$ and is most reluctant to defect $(b=1)$ by setting the quotation price slightly higher than the average procurement price $Q_{i}(t)\left(P_{\mathrm{A}_{1}}\right.$ in Figure 3$)$. We can learn from this that $P_{\mathrm{A}}$ and $P_{\mathrm{C}}$ are two extreme cases in which firm $i$ betrays the price alliance; in order to describe its price competitive strategy, we split the temptation to defect $b$ into two disjoint sections, $b \in[1,1.5]$ and $b \in[1.5,2]$, which correspond to its two defected price sections, $\left[P_{\mathrm{A}}, P_{\mathrm{B}}\right]$ and $\left[P_{\mathrm{B}}, P_{\mathrm{C}}\right]$, respectively. If firm $i$ sets its quotation price in section $\left[P_{\mathrm{B}}, P_{\mathrm{C}}\right]$, we consider it taking a moderate price competitive strategy and refer to firm $i$ as a moderate price competitor; when firm $i$ sets its quotation price in section $\left[P_{\mathrm{A}}, P_{\mathrm{B}}\right]$, we consider it taking an aggressive competitive strategy and call it an aggressive price competitor. As we know from Heil and Helsen [10], a price war is often ignited by an aggressive price competitor. For the convenience of the analysis and discussion in the following section, we use a larger temptation to defect $b(b \in[1,1.5])$ to represent a moderate competitive price strategy and a smaller temptation to defect $b(b \in[1.5,2])$ to represent an aggressive price competitive strategy.

The price described in equations (9) and (12) establishes a bridge between firm $i$ 's price competition behavior and its temptation to defect, through which the price competition and the dynamic of the SCN are coupled.

Firm $i$ gains sale revenue, but has to pay the procurement cost, the penalty cost for backlogged orders, and the inventory cost for excess products, so at the end of time step $t$, firm $i$ calculates its profits $\Pi_{i}(t)$ as follows:

$$
\begin{aligned}
\Pi_{i}(t)= & \sum_{c \in C_{i}} P_{i, c}(t) Y_{i, c}^{d}(t)-\sum_{v \in V_{i}} P_{i, v}(t) Y_{i, v}^{s}(t) \\
& -\lambda B_{i}(t)-\rho I_{i}^{\prime}(t),
\end{aligned}
$$




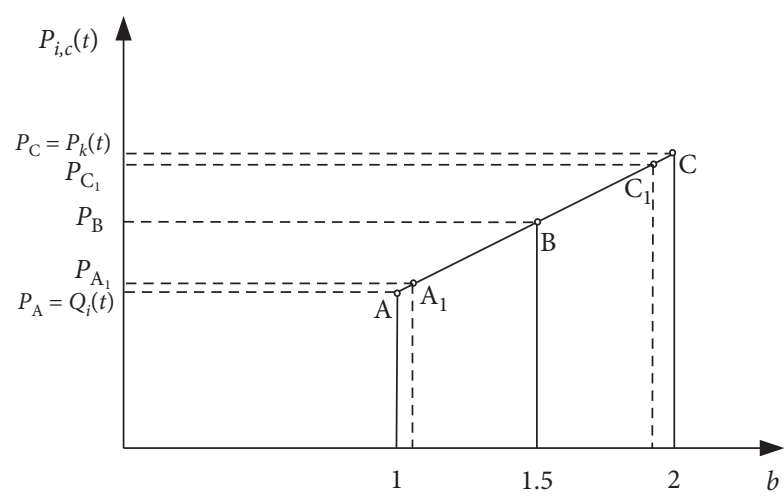

FIGURE 3: Firm $i$ 's quotation price as a function of the temptation to defect.

where $P_{i, c}(t)$ is firm $i$ 's unit selling price to single customer $c$, $P_{i, v}(t)$ is firm $i$ 's unit procurement price from single supplier $v$, if firm $i(v)$ is a cooperator, the price $P_{i, c}(t)\left(P_{i, v}(t)\right)$ for its customer $c(i)$ is calculated by equation (9); if firm $i$ is a defector, the quotation price for its potential customer $c$ is calculated by equation (12) with the temptation to defect $b . \lambda$ is the unit stock-out cost for a backlogged order and $\rho$ is the unit inventory cost for excess products. For simplicity, we do not consider the production cost here. Finally, firm $i$ updates its total capital in time step $t$ described by the following equation:

$$
A_{i}(t)=A_{i}(t-1)+\Pi_{i}(t)
$$

where $A_{i}(t)$ is firm $i$ 's total capital up to time step $t$.

2.3.3. Price Evolution. As we discussed above, the neighbors are firms located in the same stage of the SCN. Firm $i$ and its neighbors cooperate and compete in order to fight for customers and the market, so business relations exist although there are no direct links between them. Considering this, the definition of neighbors of firms in an SCN is business-related instead of network structure-based as defined by most studies [17-26]. Thus, firm $i$ 's neighbors should have a business relation to firm $i$, which is found as follows.

Firstly, we find firm $i$ 's all potential customers $C_{i}$, then we iterate the potential customers $C_{i}$ and obtain all the candidate firms of each customer one by one; all the firms (except firm $i$ ) that we find are firm i's neighbors.

In Figure 4, firm $i$ has three potential customers $a, c$, and $e$. For the three potential customers, besides their common candidate firm $i$, potential customers $a$ and $c$ have another candidate firm $g$, and potential customer $e$ also has another candidate firm $j$. According to the definition of neighbors in an SCN, we know that firm $i$ has two neighbors, which are firms $g$ and $j$; similarly, firm $g$ 's neighbors are firms $i$ and $f$.

From the abovementioned definition of neighbors in an $\mathrm{SCN}$, we can see clearly that firm $i$ shares common potential customers with each of its neighbors, respectively, i.e., firm $i$ and its neighboring firm $g$ have potential customer $a$ in common, and it also shares common customer $e$ with its neighboring firm $j$; firm $i$ and its neighbor must compete for the orders from their common customers, showing that the

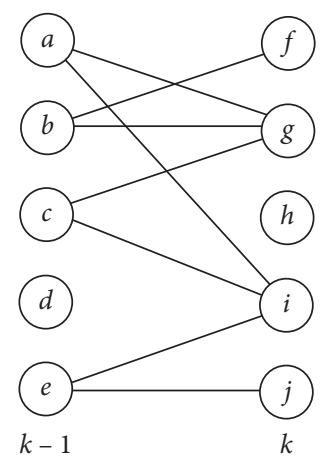

FIGURE 4: Illustration of business-related neighbors in an SCN.

definition of neighbors in an SCN is business-related. It should be noted that the network structure of the SCN in our model is fixed from the outset and neighbors in the SCN never disconnect or reconnect by price competition and dynamic of the SCN.

We can also see that the size of firm i's neighbors depends on the average candidate firms of its potential customers. More average candidate firms bring about more neighbors for firm $i$, which results in a larger game scope and game round for firm $i$ because it needs to play PDGs with all of its neighbors, respectively, meaning that firm $i$ is closely connected to the other firms in its industry, so we can take the average candidate firms to denote its business connectivity to the other firms in its industry.

In each time step $t$, firm $i$ interacts and plays a PDG with each neighbor, respectively. If firm $i$ is a cooperator, the quotation price $P_{i, c}(t)$ for its potential customer $c$ is calculated according to equation (9); otherwise, if firm $i$ is a defector, the quotation price for its potential customer $c$ is calculated according to equation (12) with the temptation to defect $b$. The total pay-off of firm $i$ is the sum of all the interactions and can be expressed as follows:

$$
G_{i}=\sum_{j \in \Psi_{i}} U_{i}^{T} W U_{j},
$$

where $\Psi_{i}$ denotes firm i's neighbors. Having completed PDGs with all its neighbors, firm $i$ and its neighbors send quotations to their potential customers, respectively, and their potential customers will try to select the firm offering the lowest quotation price as their supplier in the next time step. However, it is well known that potential customers cannot always be lucky enough to find the firm with the lowest quotation price in a complicated market environment, so to make our model more practical, we introduce the price defectors' exposure rate $\gamma$ to indicate the probability of potential customers finding the price defector with the lowest quotation. In a price-based PDG, a random number between 0 and 1 is generated; if the random number is less than the defectors' exposure rate $\gamma$, the potential customers are not lucky enough to find the firm with the lowest quotation, and the supplier that provided products in the last time step is reselected as the supplier.

After each round of the game, firm $i$ will inspect its neighbors' pay-offs, change its strategy in the next time 
according to the comparisons, and revise its strategy by selecting one of its neighbors $j$ with a probability $Z_{S_{i} \longleftarrow S_{j}}$ in terms of a preferential selection rule:

$$
Z_{S_{i} \longleftarrow S_{j}}=\frac{1}{1+\exp \left[\left(G_{i}-G_{j}\right) / H\right]},
$$

here $H$ indicates the choice noise. $H \longrightarrow \infty$ leads to firm $i$ 's neutral (random) drift, whereas $H=0$ means that firm $i$ will definitely choose the strategy that will generate more payoffs. In our model, all the firms update their strategies synchronously. It should be mentioned that firm $i$ only knows each of its neighbors' game strategies and pay-offs, and it cannot get its neighbors' detailed operational information, such as procurement price, sale price, and backlogged orders, which means firm $i$ cannot calculate its neighbors' profits according to equation (13), firm $i$ only think that its neighbor $j$ with higher pay-off will win more customers, so firm $i$ follows suite by revising its strategy according to equation (16).

The main differences between our model and previous works deserve a further discussion here. First, and most importantly, we contribute to the literature by extending the price war from a single industry to the whole SCN, and we model the price competition between cooperators and defectors as a multistage evolutionary PDG in the SCN; secondly, the neighbors of a firm in an SCN are based on the firm's business relation instead of the network structure; lastly, in our model, the firms' quotation price is mapped into the temptation to defect of the PDG when firms are price defectors, so the price competition and dynamic of the SCN are coupled and we can investigate the coevolution between them in just one model. Moreover, the differences between our models and previous works on supply chain dynamics [35-37] lie in our incorporation of the price competition into the dynamic of the SCN.

\section{Simulation and Results}

The simulation model is built up by the agent-based approach implemented with Repast [39]. Our implementation is inspired by the classic "beer game" agent-based model presented by North and Macal [40], we extend it to a networked "beer game" agent-based model and add game ability to the middlemen agent's in the following: Add PDGrelated methods: (1) playGameWithAllNeighbor(), which plays price-based PDG games with its neighbors; (2) calculateTotalPayOff(), which calculates the total pay-off of its n-round PDGs; (3) transferStrategy(), which changes its game strategy in the next time. And also we override the middlemen agent's selectSupplierFromCandidateFirms() method by selecting the candidate firms with lowest quotation as their supplier in the next step. The main purpose of the simulation is to study how a price war affects the performance of an SCN and how to contain a price war in an SCN effectively; therefore, all the simulations are focused on this effect. For the simulations, we consider an SCN with 3000 nodes $(N=3000)$ that are evenly distributed across six stages $(K=6)$. In the simulation model, we set the selling price of all the manufacturers in the last stage as $1\left(P_{K}(t)=1\right)$, the unit stock-out cost is $20 \%$ of a firm's average selling price $(\lambda=0.2)$, and the unit inventory cost is $10 \%$ of a firm's average selling price $(\rho=0.1)$; a firm forecasts its demand based on the 4 latest past actual demands $(l=4)$ and the firm's choice noise is $H=10$ when it wants to revise its game strategy in the next time step.

For simplicity, we use initial cooperators $\eta$ to denote the size of price alliance, and we use the average candidate firms $S$ to denote the business connectivity of industries.

In order to investigate the damage to the SCN caused by a price war, the performance of the SCN proposed by Mizgier et al. [37] is used, which is given by

$$
M(t)=\frac{A_{\text {total }}(t)}{Y_{\text {total }}(t)} \times 100 \%,
$$

where $A_{\text {total }}(t)$ is the aggregated capital of the whole SCN in time step $t, Y_{\text {total }}(t)$ is the total delivered products in time step $t$, and $M(t)$ is the measure of the percentage of the working capital utilized in the SCN. In each time step, consumers, middlemen, and manufacturers act successively from downstream to upstream according to their behaviors defined in Figure 2; at the end of each time step, all the middlemen calculate their profits $\Pi_{i}(t)$ gained in the current time step according to equation (13) and update their total capital $A_{i}(t)$ according to equation (14). Subsequently, we determine the performance of the SCN $M(t)$ according to equation (17). The initial inventory of the retailers, wholesalers, and manufacturers was randomly generated, so at the beginning stage of simulation, the firms such as retailers, wholesalers, and manufacturers in the SCN may face backorder; moreover, all firms forecast their demand based on the 4 latest past actual demands, and this may cause large fluctuations in inventory and orders. Considering this, the final results shown below were averaged over 200 time steps after 1000 transient time steps; moreover, each data point averages over 100 realizations of same setting to warrant the appropriate accuracy.

Figure 5 shows the results for the performance of SCN for different values of the price defectors' exposure rate $\gamma$; it shows that when $\gamma<0.2$, a price defector hardly causes any damage to the SCN, but the performance of the SCN $M(t)$ decreases monotonously with the increment of the price defectors' exposure rate $\gamma$ when $\gamma>0.2$. The reason is simple and straightforward; when the price defectors' exposure rate $\gamma$ is low, the potential customers face a lower probability of finding the lowest price defector, so they buy the products from the price alliance at the contracted price agreed by the price alliance; in this case, a price defector's malicious markdown can hardly bring any damage to the performance of the SCN, but when the price defector increases its exposure rate $\gamma$, the potential customers can find it easily and buy products from it at a very low price, which leads to huge damage to the performance of the SCN. We can learn from Figure 5(a) that if some firms take a moderate price competitive strategy $(b=1.6$ and $b=1.8$ in Figure $5(a))$, the damage to the performance of the SCN caused by their price markdown behavior is not particularly serious, but the price 


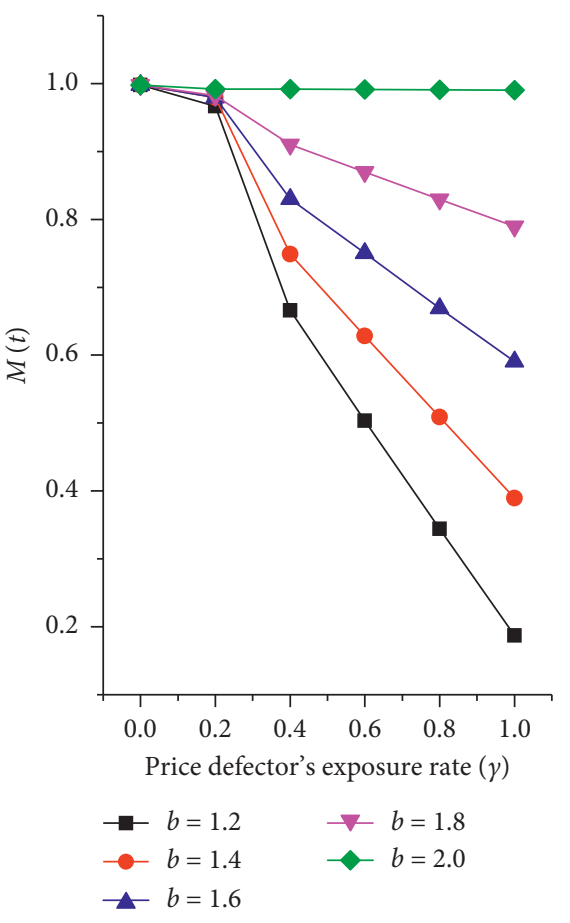

(a)

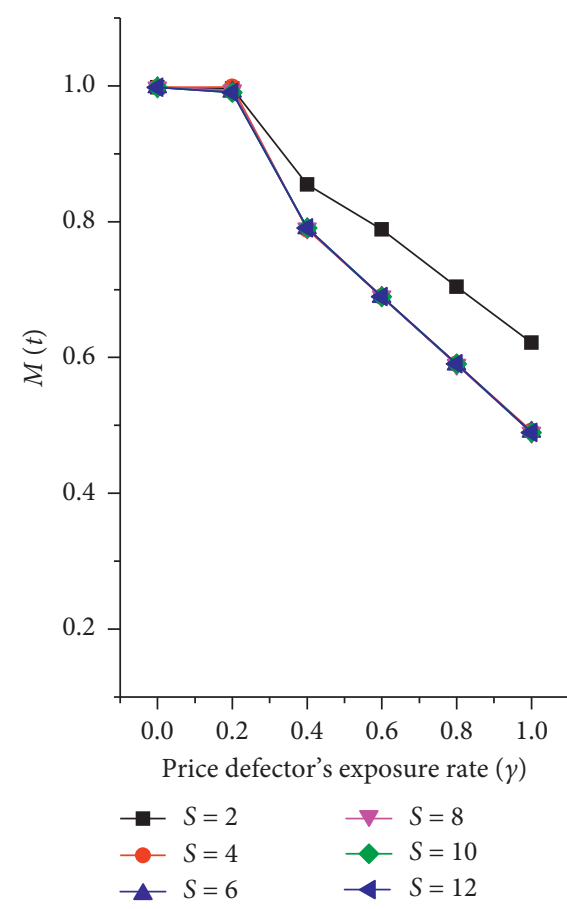

(b)

FIGURE 5: (a) The performance of the SCN as a function of the defectors' exposure rate $\gamma$ for different temptations to defect $b$ when $\eta=0.6$ and $S=6$. (b) The performance of the SCN as a function of the defectors' exposure rate $\gamma$ for different $S$ when $\eta=0.6$ and $b=1.5$ (here, $\eta, S$, and $b$ denote the size of price alliance, average candidate firms, and temptation to defect, respectively).

alliance should work together and take measures to prevent moderate price competitive behavior from developing into malicious price markdown $(b=1.2$ and $b=1.4$ in Figure 5(a)). Figure 5 also tells us that a smaller temptation to defect $b$ leads to a lower performance of the SCN with the same exposure rate $\gamma$, which means that although most firms are unlikely to taking an aggressive competitive strategy in the price competition, even a small number of firms take this strategy and try their best to make it public to their potential customers, and they will win the most potential customers but also lead other firms to follow suit, bringing heavy damage to the performance of the SCN. This tells us that in a price-based competition environment, price defectors that cut their price maliciously and promote their strategy can cause huge damage to the SCN. We can confirm this conclusion in Figure 5(b), in which the performances of the SCN $M(t)$ as a function of the defector exposure rate $\gamma$ for different $S$ for different average candidate firms $(S=4, S=6, S=8, S=10$, and $S=12)$ are overlapping, which indicates clearly that the damage to performances of the SCN caused by the price defectors' exposure rate $\gamma$ is independent of the business connectivity of the SCN when $S>2$. It is well known that aggressive competitors cutting their selling price maliciously and improving their exposure are an essential characteristic of the price competition in online retailing. Online retailers feature a huge amount of potential customers and various marketing strategies; once they cut their selling price maliciously and make it public, a price war will break out easily and reach a large extent in a very short period of time. China's most famous recent price war in the online home appliance industry is the best example in this respect [9]. Therefore, we have result 1 as follows.

Aggressive price competitors' marketing power and their exposure rate are the key factor leading to the price avalanche in price wars. The price alliance should take measures to lower the price defectors' public exposure at the preliminary stage of the price competition.

The next issue is whether the SCN structure has impacts on the evolution of price competition between price cooperators and defectors. In our model, the SCN structure is denoted by the average candidate firms $S$ and the simulation results are shown in Figure 6. It shows that when the price defectors' exposure rate is constant, the price defectors take an aggressive competitive strategy $(b=1.2 \sim 1.4)$; the price alliance cannot stop the malicious price markdown spreading in the SCN with relatively smaller average candidate firms ( $S=2$ and $S=4$ in Figure 6(a)), but the price alliance in the SCN with relatively larger average candidate firms $(S=6, S=8, S=10$, and $S=12$ in Figure 6(a)) can prevent a price markdown from spreading effectively, which tells us that the SCN structure plays an important role in the effect of price alliances' suppression of price wars when the price defectors take an aggressive competitive strategy. We can also see clearly from Figure 6(a) that when $b>1.4$ and $S>2$, the performance of the SCN as a function of the temptation to defect for different average candidate firms are overlapping, which means that the SCN structure has little 


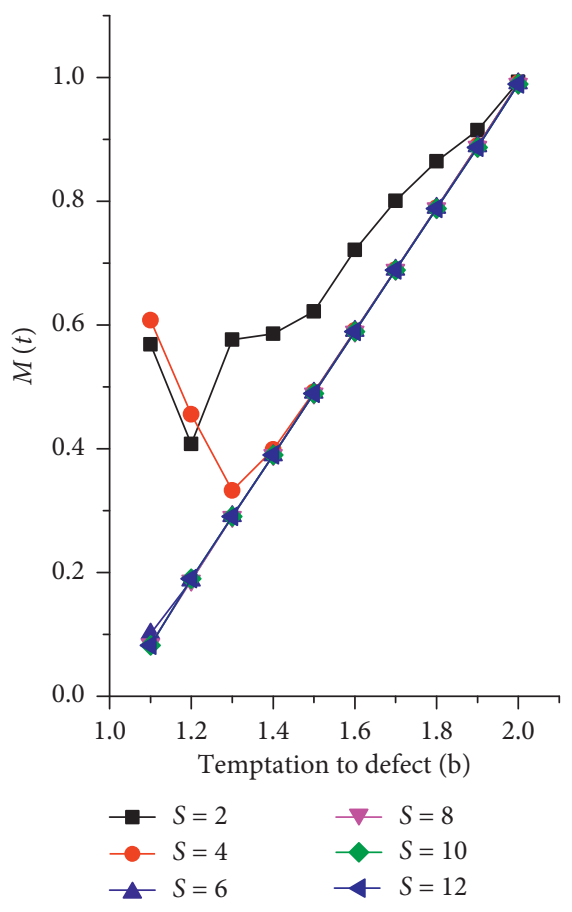

(a)

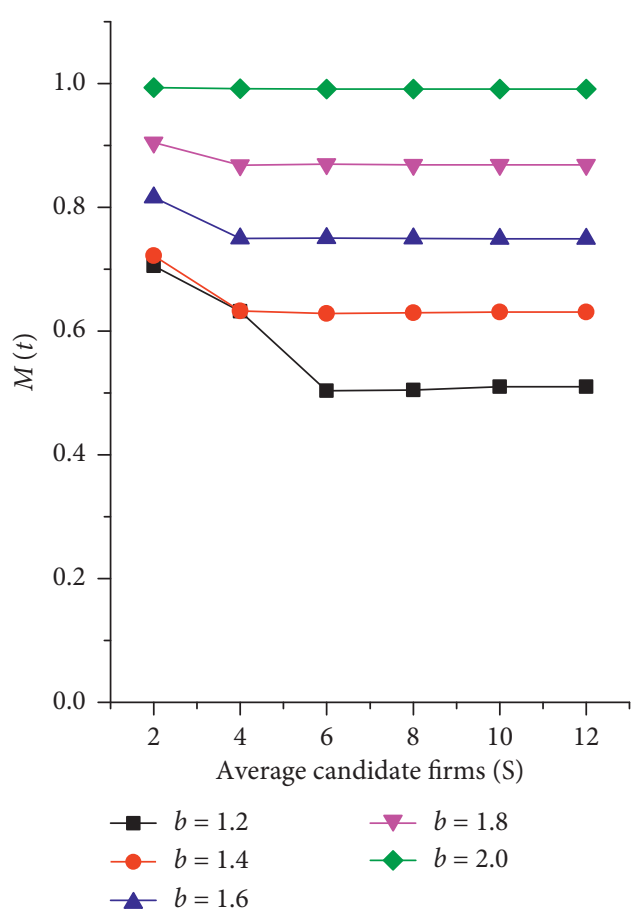

(b)

FIgURE 6: (a) The performance of the SCN as a function of the temptation to defect for different average candidate firms $S$ when $\eta=0.6$, $\gamma=1.0$. (b) The performance of the SCN as a function of average candidate firms $S$ for different temptations to defect when $\eta=0.6$ and $\gamma=1.0$ (here, $\eta$ and $\gamma$ denote the size of price alliance and the defectors' exposure rate, respectively).

relation to the effect of price alliances' suppression of the price war when the price defectors take a moderate competitive strategy. The result can be further confirmed by Figure 6(b), which provides us with another point of view: when the price defectors take an aggressive strategy, the price alliance cannot gain the power in containing the price war until the SCN's average candidate firms are greater than 6. As we discussed in Section 2.3.3, the SCN's average candidate supplier can be regarded as the business connectivity of industries in the SCN, so we can learn from this that the business connectivity of industries has a direct impact on the price alliance's capability to contain the price war. A closely connected industry cannot suffer a price war easily because of its price alliance's capability of containing the price war, whereas a loosely connected industry often suffers from price wars. Therefore, we have result 2 as follows.

An SCN with closely connected industries cannot suffer a price war easily, and firms in the SCN should increase their exchanges and cooperation from the very beginning to prevent price wars.

As we have mentioned before, a price alliance is a common practice to contain price wars: does it always make sense? Here we investigate further the effects of a price alliance's size on its ability to contain a price war in an SCN. In our model, we use initial cooperators $\eta$ in each stage of the SCN as the price alliance's size and the relevant simulation result are presented in Figure 7. (a), (b), (c), and (d) in Figure 7 correspond to an SCN with average candidate firms $S=4, S=6, S=8$, and $S=10$, respectively. We can know from the simulation results that only if the price alliance's size reaches $80 \%$ of the total firms in the industry can the price alliance gain the power to contain the price war effectively, which is irrelevant to price competitive strategy the price defectors take. We can see from Figures $7(a)-7(d)$ that the result works well independently of the SCN's structure. Therefore, we have result 3 as follows.

In order to contain the price wars in an SCN effectively, a price alliance should invite as many firms as possible to sign a price cooperating contract.

It should be noted that our model minimizes the inventory impacts on the performance of the SCN because we want to investigate fully the price competition's effect on the performance of the SCN. Since many studies have reported that the inventory plays an important role in the performance of the SCN, the last question arising is whether our results still hold when the inventory is considered. According to References [36, 37, 40], the fluctuation in the end-consumers' demand is an important factor that contributes to the inventory of the SCN, so we incorporate the inventory into our model by adding the fluctuation in the end-consumers' demand according to the law:

$$
D_{i}(t)=D_{i} * d_{i},
$$

where $D_{i}(t)$ is the demand of end-consumer $i$ in time step $t$ and $D_{i}$ and $d_{i}$ are the average demand and demand fluctuation of end-consumer $i$, respectively. $d_{i}$ is a random variable that is uniformly distributed in $[1-\theta, 1+\theta]$ and independent of end-consumer $i$ 's average demand $D_{i}$. Subsequently, we can further investigate whether the price 


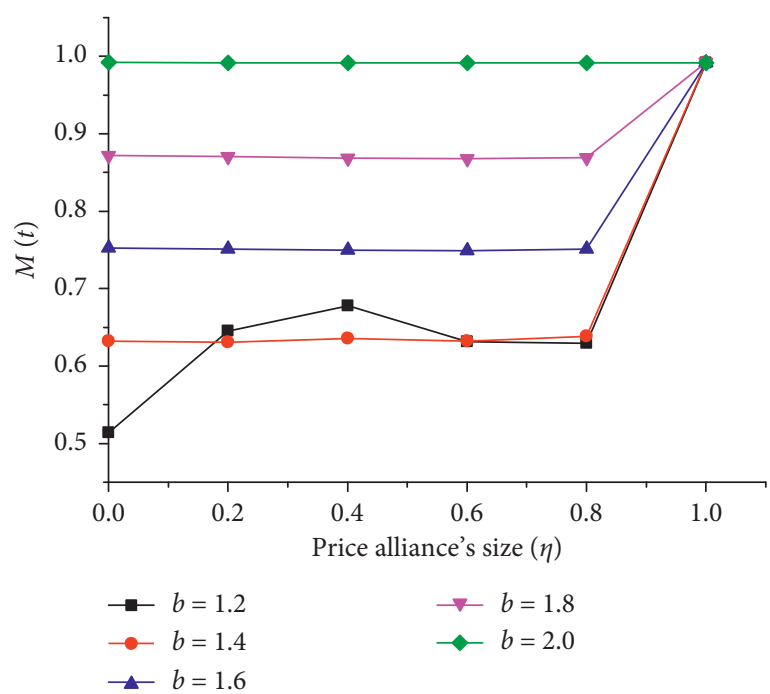

(a)

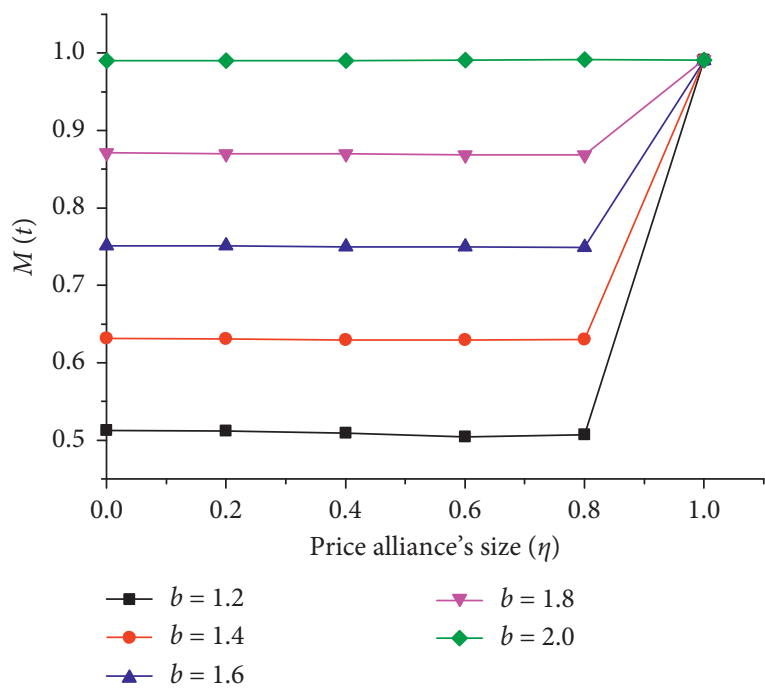

(c)

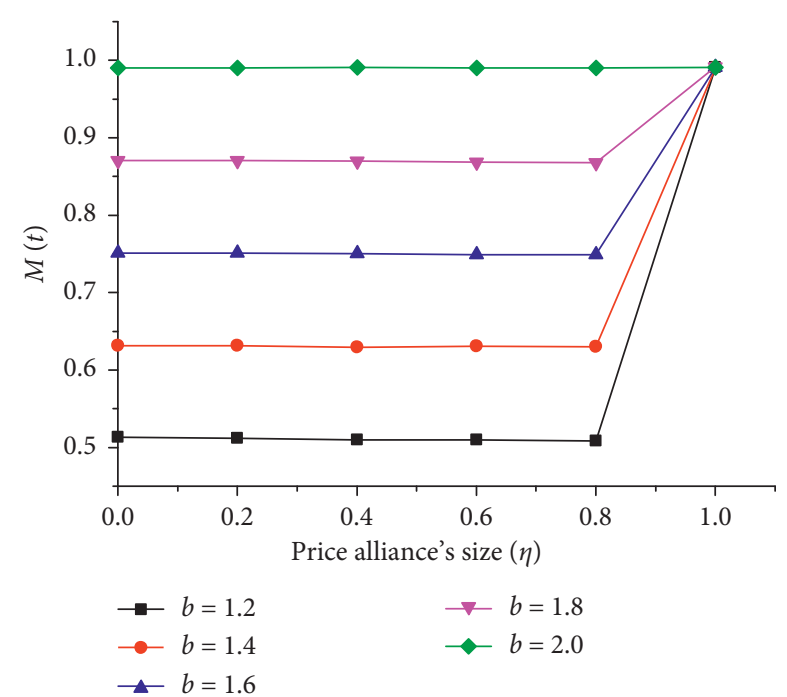

(b)

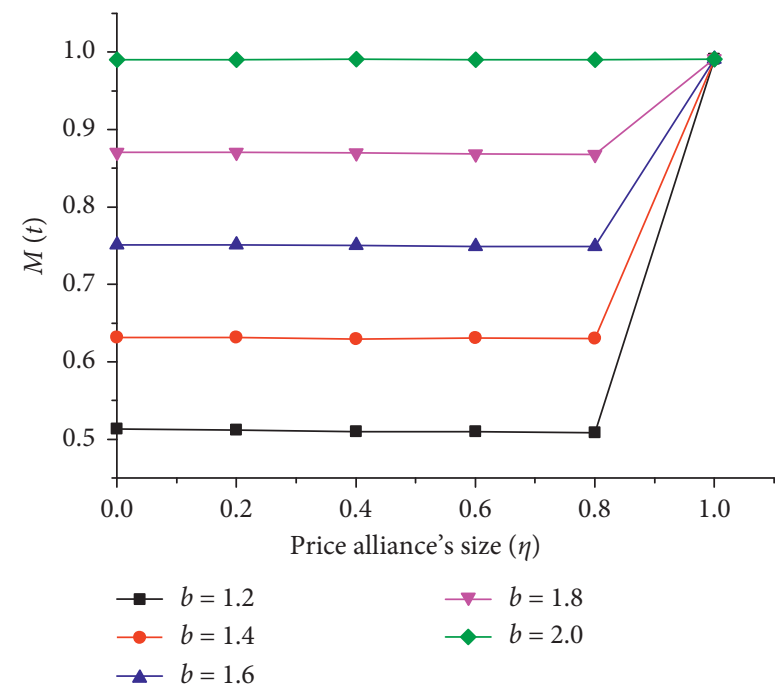

(d)

FIGURE 7: The performance of the SCN as a function of the size of price alliance $\eta$ in a price alliance for different temptations to defect $b$ when $\gamma=1.0$ : (a) $S=4$, (b) $S=6$, (c) $S=8$, and (d) $S=10$ (here, $\gamma$ and $S$ denote the SCN's defectors' exposure rate and average candidate firms, respectively).

alliance can stop the malicious price markdown spreading in the SCN when the inventory is considered. For a reference, we want to observe the performance of the SCN with only the consumers' demand fluctuation taken into consideration, so we set all the firms in the SCN as price cooperators and all the end-consumers' demand as fluctuating according to equation (18). The simulation result is shown in Figure 8(a), which tells us that the performance of the SCN becomes poor with the inventory incurred by the endconsumer's demand fluctuation, a result that is also reported in many studies. After that, we simulate the performance of the SCN as a function of the temptation to defect when both inventory and price competitions are considered and the simulation result is shown in Figure 8(b). Figure 8(b) shows that the damage to the performance of the SCN caused by the price markdown is not so serious when the fluctuation range of the end-consumers' demand is small $(\theta=0.2$ and $\theta=0.4)$. Moreover, even when the end-consumers' demand fluctuates markedly $(\theta=0.6$ and $\theta=0.8)$, the damage to the performance of the SCN caused by the price markdown is not especially serious when the firms in the SCN take a moderate price competitive strategy $(b>1.6)$. The only exception is when firms take an aggressive price competitive strategy $(0<b<1.6)$ in a violently fluctuating market $(\theta=0.6$ and $\theta=0.8)$. The result of the simulation further indicates that the price alliance still has the ability to contain the price war in the SCN even when the inventory is considered in most cases.

\section{Conclusion}

In this paper, price wars are extended to SCNs and modelled as multistage price-based evolutionary PDGs. In the model, we incorporate the price competition into the dynamic of the 


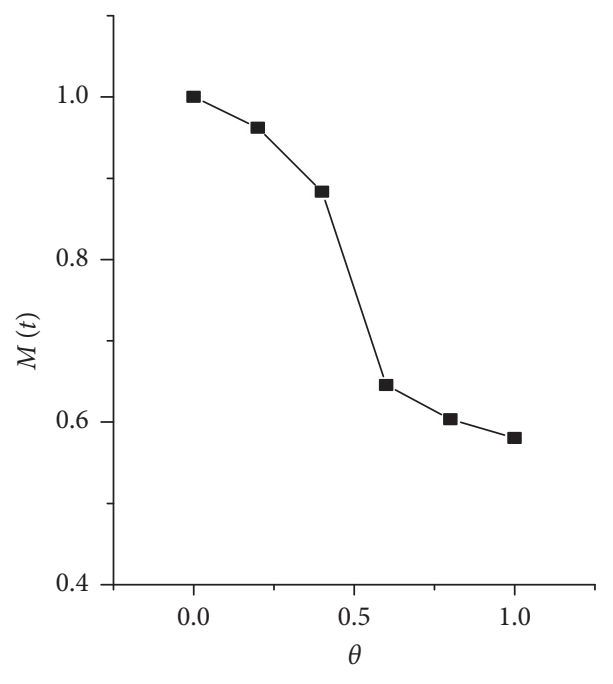

(a)

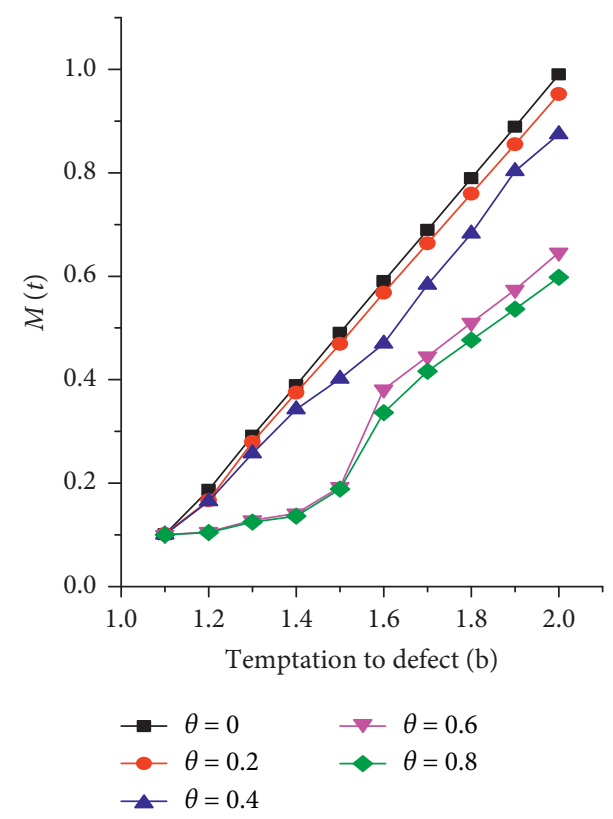

(b)

FIgURE 8: (a) The performance of the SCN as a function of the end-consumers' demand fluctuation. (b) The performance of the SCN as a function of the temptation to defect for different consumer demand fluctuations when $\eta=0.6, \gamma=1.0$, and $S=8$ (here, $\eta, \gamma$, and $S$ denote the size of price alliance, the defectors' exposure rate, and the average candidate firms, respectively).

SCN by establishing the relation between firms' quotation price and the temptation to defect of PDGs, and we focus on how price wars affect the performance of the SCN and how to contain price wars. From the agent-based simulation, we find that the malicious price defectors' exposure rate, the business connectivity of the SCN, and the size of the price alliance have direct impacts on the price alliance's capability of containing the price war; the price alliance should unite more partners in the SCN than in a single industry to contain the price war effectively. To a certain extent, the simulation results can shed some light on the understanding of the mechanism of price cooperating and competitive behavior in SCNs. Moreover, our model supplements the previous works by incorporating price competition into the traditional dynamic of the SCN, which gives us new insights into the interplay between the network strategies and the dynamic of the SCN. It should be noted that the network structure of the SCN in our model is fixed from the outset and not affected by the evolutionary dynamic of the SCN. However, it is well known that firms in SCNs can face bankruptcy if their working capital hits the threshold level, and they can also be reborn by acquiring new investments, so firms' bankruptcy and rebirth process can lead the structure of the SCN to coevolve with the price competition and dynamic of the SCN. The entangled evolution of the network structure, price competition, and dynamic of the SCN make the price war in the SCN more complicated, so it is necessary to explore their behavior and features in order to determine the key factors that facilitate the price alliance to contain the price war.

\section{Appendix}

The outlines of the algorithms for java class in our model.

\section{* GamesInfo class}

(1) Create 2 reference variables of the String class type:

(1) String named me for representing the first player's name in PDG.

(2) String named opponent for representing the second player's name in PDG.

(2) Create 2 variables of the int type:

(1) int named myStrategy for representing the strategy of the first player in PDG.

(2) int named opponentStrategy for representing the strategy of the second player in PDG.

(3) Create 2 variables of the float type:

(1) float named myPayoff for representing the payoff of the first player in PDG.

(2) float named opponentPayoff for representing the pay-off of the second player in PDG.

(4) Create 2 variables of the double type:

(1) double named myPrice for representing the quotation price of the first player in PDG.

(2) double named opponentPrice for representing the quotation price of the second player in PDG. 


\section{* Order class}

(1) Create 2 reference variables of the String class type:

(1) String named fromAgent for representing name of the agent which sends the order.

(2) String named toAgent for representing name of the agent which receives the order.

(2) Create 2 variables of the double type:

(1) double named quantity for representing the quantity of the order.

(2) double named price for representing the price of the order.

\section{*Shipment class}

(1) Create 2 reference variables of the String class type:

(1) String named fromAgent for representing name of the agent which sends the shipment.

(2) String named toAgent for representing name of the agent which receives the shipment.

(2) Create 2 variables of the double type:

(1) double named quantity for representing the quantity of the shipment.

(2) double named price for representing the price of the shipment.

\section{$*$ Network Edge class}

(1) Create 3 reference variables of the LinkedList class type:

(1) LinkedList<GamesInfo > named gameInfoQueue for storing the result of PDG and quotation price of the competing firms.

(2) LinkedList<Shipment> named shipmentQueue for storing shipments to downstream stage.

(3) LinkedList<Order> named orderQueue for storing orders to suppliers in the upstream stage.

(2) Define the following methods which are needed by the agents during their interactions:

(1) sendGameInfoToDownStreamStage() inserts a value to the end of the gameInfoQueue.

(2) receiveGameInfoFrom UpStreamStage() retrieves all values in the gameInfoQueue, and deletes them.

(3) sendShipmentToDownStreamStage() inserts a value to the end of the shipmentQueue.

(4) receiveShipmentFrom UpStreamStage() retrieves all values in the shipmentQueue, and deletes them.

(5) sendOrderToUpStreamStage() inserts a value to the end of the orderQueue.

(6) receiveOrderFromDownStreamStage() retrieves all values in the orderQueue, and deletes them.

\section{* Consumer Agent class}

Define step() method which executes the following methods for each agent generated from this class:

(1) ReceiveShipmentFromUpStreamStage() retrieves a shipment from each of its $N$ upstream suppliers by calling the method receiveShipmentFromUpStreamStage() defined in the $*$ NetworkEdge class.

(2) ReceiveGameInfoFromUpStreamStage() retrieves all results of PDG and quotation price by calling the method receiveGameInfoFrom UpStreamStage() defined in the $*$ NetworkEdge class.

(3) GenerateDemmandofNextTimeStep() generates consumer's demand of the next time step according to the law as follows:

(1) Constants when the inventory is not considered;

(2) According to equation (18) when the inventory is considered.

(4) SelectSupplierFromCandidateFirms() selects the supplier which offer the lowest quotation from its candidate firms.

(5) SendOrderToSupplier() sends out an order by calling the method sendOrderToUpStreamStage() defined in the $*$ NetworkEdge class.

\section{* Middleman Agent class}

Define step() method which executes the followings methods for each agent generated from this class:

(1) ReceiveShipmentFromUpStreamStage() retrieves a shipment from each of its $N$ upstream suppliers by calling the method receiveShipmentFromUpStreamStage() defined in the $*$ NetworkEdge class, then aggregate the shipments.

(2) ReceiveGameInfoFromUpStreamStage() retrieves the result of PDG and quotation price from each of its $\mathrm{N}$ upstream candidate firms by calling the method receiveGameInfoFrom UpStreamStage() defined in the $*$ NetworkEdge class.

(3) UpdateInventoryAftGetShipment() update available inventory of current time step.

(4) ReceiveOrderFromDownStreamStage() retrieves an order from each of its $\mathrm{N}$ downstream customers by calling the method receiveOrderFromDown StreamStage() defined in the $*$ NetworkEdge class.

(5) SendShipmentToDownStreamStage() delivers a shipment to each of its $N$ downstream customers by calling the method sendShipmentToDownStreamStage() defined in the $*$ NetworkEdge class.

(6) ForecastDemmanofNextTimeStep() forecasts the demand of next time step.

(7) SelectSupplierFromCandidateFirms() trys to select the supplier from its candidate firms. 
(8) SendOrderToSupplier() sends out an order by calling the method sendOrderToUpStreamStage() defined in the $*$ NetworkEdge class.

(9) Competes with its neighbors by calling the following methods:

(1) playGameWithAllNeighbor() plays price-based PDG games with its $n$ neighbors;

(2) sendGameInfoToDownStreamStage() sends the result of PDGs and quotation price by calling the method sendGameInfoToDownStreamStage() defined in the $*$ NetworkEdge class.

(3) caculateTotalPayOff() calculates the total payoff of its $n$-round PDGs.

(4) transferStrategy() changes its game strategy in the next time.

(10) CaculateTotalRevenue() calculates revenue in current time step.

(11) AggregateTotalCapital() updates total capital.

\section{*ManufacturerAgent class}

Define step() method which executes the followings methods for each agent generated from this class:

(1) ReceiveOrderFromDownStreamStage() retrieves an order from each of its $\mathrm{N}$ downstream customers by calling the method receiveOrderFromDownStreamStage() defined in the * NetworkEdge class.

(2) SendShipmentToDownStreamStage() delivers a shipment to each of its $\mathrm{N}$ downstream customers by calling the method sendShipmentToDownStreamStage() defined in the $*$ NetworkEdge class.

\section{*SCNSimModel class (controller/scheduler)}

(1) Create an array with 500 variables of the * ConsumerAgent class type, and set them at stage 1 .

(2) Create an array with 2000 variables of the $*$ MiddlemanAgent class type and divide them into 4 stage (from stage 2 to 5) with 500 variables in each stage.

(3) Create an array with 500 variables of the $*$ ManufacturerAgent class type and set them at stage 6 .

(4) Set the variables of the $*$ MiddlemanAgent class as price cooperator or price defector randomly, according to the initial cooperators $\eta$.

(5) Generate links of the * NetworkEdge class, each link connect a pair of two agents in adjacent stage according to the average candidate firms $S$.

(6) Build the simulation schedules as follows:

$$
\begin{aligned}
& \text { for } t_{m}=t_{1} \text { to } t_{T}, \quad / / T \text { is total simulation time } \\
& \text { steps. } \\
& \text { for } i=0 \text { to } 500 \\
& \text { ConsumeAgent[1][i]. step(); //Call each } \\
& \text { consumer agent's step() method. } \\
& \quad \text { end for }
\end{aligned}
$$

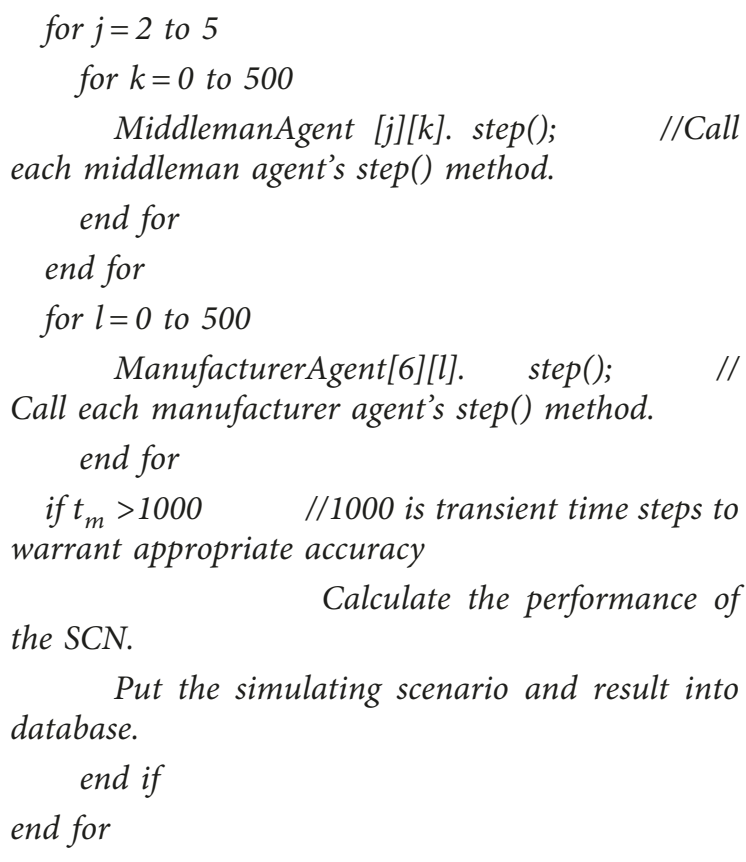

\section{* Model configuration file}

The simulations run in batch mode without GUI, and the definition of parameter setters is listed in configuration file, as follows:

runs: 1

stdDevCustomerDemand \{

start: 0.0

end: 1.0

incr: 0.1

\{

runs: 1

AvgCandidateFirms \{

start: 2

end: 12

incr: 2

\{

runs: 1

CooperateRate \{

start: 0.0

end: 1.0

incr: 0.1

\{

runs: 1

TemptationToDefect \{

start: 1.0

end: 2.0

incr: 0.1 
runs: 1

ExposureRate \{

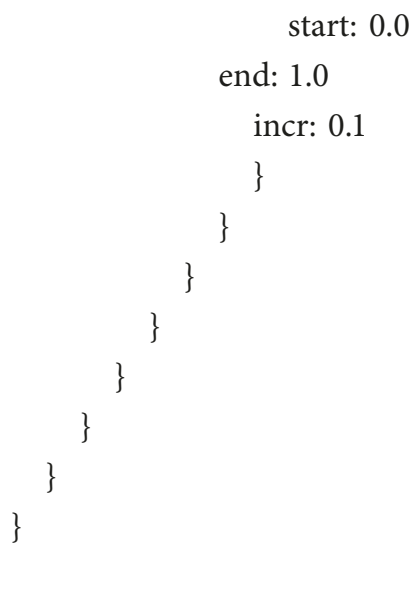

\section{Data Availability}

The data used to support the findings of this study are generated by our agent-based simulation model, and the simulation mode implementation is listed in Appendix.

\section{Conflicts of Interest}

The authors declare that there are no conflicts of interest regarding the publication of this paper.

\section{Acknowledgments}

The work is supported by the Natural Science Foundation of Jiangxi Province (No. 20181BAB201010) and National Natural Science Foundation of China (No. 71761013).

\section{References}

[1] E. J. Anderso and Y. Bao, "Price competition with integrated and decentralized supply chains," European Journal of Operational Research, vol. 200, no. 1, pp. 227-234, 2010.

[2] C.-H. Wu, "Price and service competition between new and remanufactured products in a two-echelon supply chain," International Journal of Production Economics, vol. 140, no. 1, pp. 496-507, 2012.

[3] S. Sinha and S. P. Sarmah, "Coordination and price competition in a duopoly common retailer supply chain," Computers \& Industrial Engineering, vol. 59, no. 2, pp. 280-295, 2010.

[4] J. E. Urbany and P. R. Dickson, "Competitive price-cutting momentum and pricing reactions," Marketing Letters, vol. 2, no. 4, pp. 393-402, 1991.

[5] H. Assael, Marketing, Prentice-Hall, Upper Saddle River, NJ, USA, 1990.

[6] Y. Jian, "Price war roils China market," Automotive News, vol. 86, no. 6521, p. 24, 2012.

[7] J. Gokhale and V. J. Tremblay, "Competition and price wars in the U.S. brewing industry," Journal of Wine Economics, vol. 7, no. 2, pp. 226-240, 2012.

[8] Y. Zhang and D. K. Round, "Price wars and price collusion in China's airline markets," International Journal of Industrial Organization, vol. 29, no. 4, pp. 361-372, 2011.
[9] Horizon Research Consultancy Group, "The price war in online home appliance retailers, 360 Buy and Suning," China Consumers, vol. 9, pp. 120-123, 2012.

[10] O. P. Heil and K. Helsen, "Toward an understanding of price wars: their nature and how they erupt," International Journal of Research in Marketing, vol. 18, no. 1-2, pp. 83-98, 2001.

[11] G. A. Hay and D. Kelley, "An empirical survey of price fixing conspiracies," The Journal of Law and Economics, vol. 17, no. 1, pp. 13-38, 1974.

[12] W. WengGuang, Competition behavior in structural overcapacity economy-taking color TV as example, Management World, vol. 17, no. 1, pp. 170-177, 2001.

[13] T. Sandler, "Alliance formation, alliance expansion, and the core," Journal of Conflict Resolution, vol. 43, no. 6, pp. 727747, 1999.

[14] H. Gintis, Game Theory Evolving, Princeton University Press, Princeton, NJ, USA, 2000.

[15] J. von Neumann and O. Morgenstern, Theory of Games and Economic Behavior, Princeton University Press, Princeton, NJ, USA, 1944.

[16] M. Nagarajan and G. Sošić, "Game-theoretic analysis of cooperation among supply chain agents: review and extensions," European Journal of Operational Research, vol. 187, no. 3, pp. 719-745, 2008.

[17] R. Axelrod and W. Hamilton, "The evolution of cooperation," Science, vol. 211, no. 4489, pp. 1390-1396, 1981.

[18] G. Szabó, C. Tőke, Evolutionary prisoner's dilemma game on a square lattice," Physical Review E, vol. 58, no. 1, pp. 69-73, 1998.

[19] G. Szabó and C. Hauert, "Phase transitions and volunteering in spatial public goods games," Physical Review Letters, vol. 89, no. 11, p. 118101, 2002.

[20] G. Szabó, J. Vukov, and A. Szolnoki, "Phase diagrams for an evolutionary prisoner's dilemma game on two-dimensional lattices," Physical Review E, vol. 72, no. 4, Article ID 047107, 2005.

[21] M. Kuperman and G. Abramson, "Small world effect in an epidemiological model," Physical Review Letters, vol. 86, no. 13, pp. 2909-2912, 2000.

[22] N. Masuda and K. Aihara, "Spatial prisoner's dilemma optimally played in small-world networks," Physics Letters A, vol. 313, no. 1-2, pp. 55-61, 2003.

[23] M. Tomassini, L. Luthi, and M. Giacobini, "Hawks and doves on small-world networks," Physical Review E, vol. 73, no. 1, pp. 16-32, 2006.

[24] F. C. Santos and J. M. Pacheco, "Scale-free networks provide a unifying framework for the emergence of cooperation," Physical Review Letters, vol. 95, no. 9, pp. 98-104, 2005.

[25] F. C. Santos, J. M. Pacheco, and T. Lenaerts, "Cooperation prevails when individuals adjust their social ties," PLoS Computational Biology, vol. 2, no. 10, pp. 1284-1291, 2006.

[26] F. C. Santos, J. M. Pacheco, and T. Lenaerts, "Evolutionary dynamics of social dilemmas in structured heterogeneous populations," Proceedings of the National Academy of Sciences, vol. 103, no. 9, pp. 3490-3494, 2006.

[27] R. H. Porter, "Optimal cartel trigger price strategies," Journal of Economic Theory, vol. 29, no. 2, pp. 313-338, 1983.

[28] E. J. Green and R. H. Porter, "Noncooperative collusion under imperfect price information," Econometrica, vol. 52, no. 1, pp. 87-100, 1984.

[29] W. Paul, C. Dobson, and D. Sinclair, "On the possibility of price wars when firms use a "tit-for-tat" strategy," Economics Letters, vol. 32, no. 2, pp. 115-119, 1990. 
[30] D. Dunne, "Avoiding price wars using game theory to show they are destructive and unprofitable," Ivey Business Quarterly, vol. 62, no. 4, p. 38, 1998.

[31] C. M. Harland, "Supply chain management: relationships, chains and networks," British Journal of Management, vol. 7, no. s1, pp. S63-S80, 1996.

[32] T. Y. Choi, K. J. Dooley, and M. Rungtusanatham, "Supply networks and complex adaptive system control versus emergence," Journal of Operations Management, vol. 19, no. 3, pp. 351-366, 2001.

[33] A. Surana, S. Kumara, M. Greaves, and U. N. Raghavan, "Supply-chain networks: a complex adaptive systems perspective," International Journal of Production Research, vol. 43, no. 20, pp. 4235-4265, 2005.

[34] M. A. Bellamy and R. C. Basole, "Network analysis of supply chain systems: a systematic review and future research," Systems Engineering, vol. 16, no. 2, pp. 235-249, 2013.

[35] J. M. Swaminathan, S. F. Smith, and N. M. Sadeh, "Modeling supply chain dynamics: a multiagent approach," Decision Sciences, vol. 29, no. 3, pp. 607-632, 1998.

[36] G. Weisbuch and S. Battiston, "From production networks to geographical economics," Journal of Economic Behavior \& Organization, vol. 64, no. 3-4, pp. 448-469, 2007.

[37] K. J. Mizgier, S. M. Wagner, and J. A. Holyst, "Modeling defaults of companies in multi-stage supply chain networks," International Journal of Production Economics, vol. 135, no. 1, pp. 14-23, 2012.

[38] M. A. Nowak and R. M. May, "Evolutionary games and spatial chaos," Nature, vol. 359, no. 6398, pp. 826-829, 1992.

[39] M. J. North, N. T. Collier, and J. R. Vos, "Experiences creating three implementations of the repast agent modeling toolkit," ACM Transactions on Modeling and Computer Simulation, vol. 16, no. 1, pp. 1-25, 2006.

[40] M. J. North and C. M. Macal, The Beer Dock: Three and a Half Implementations of the Beer Distribution Gamse, University of Notre Dame, Notre Dame, IN, USA, 2002. 


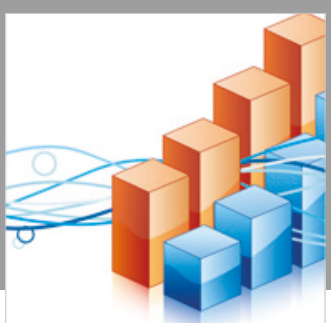

Advances in

Operations Research

\section{-n-m}
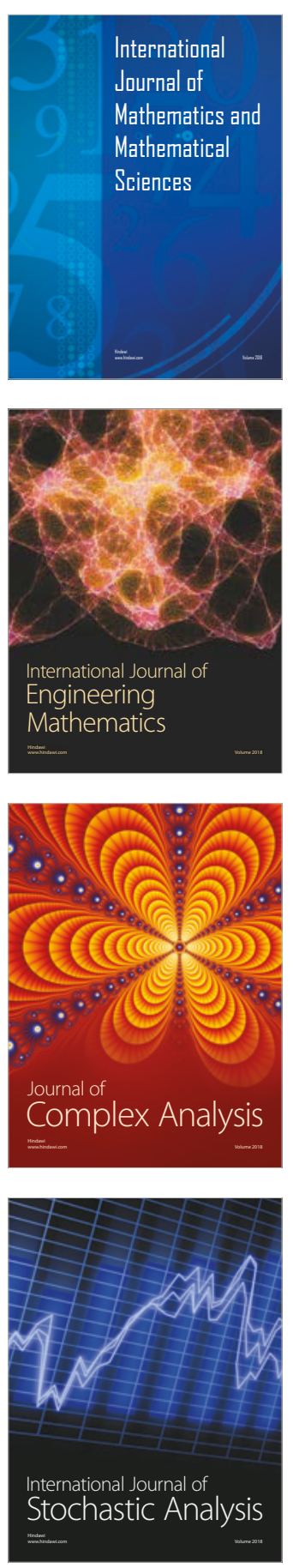
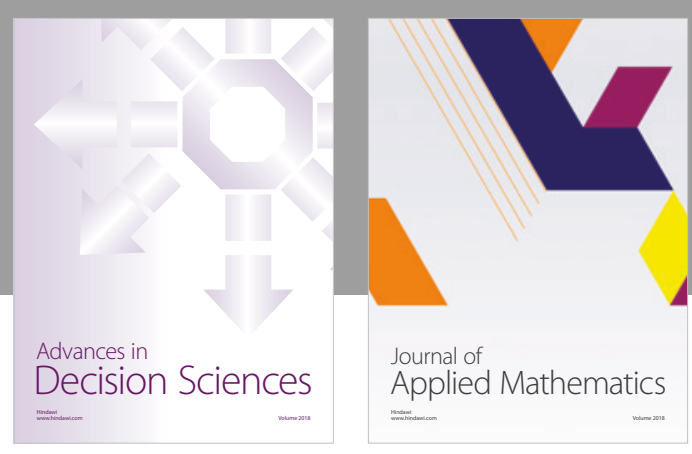

Journal of

Applied Mathematics
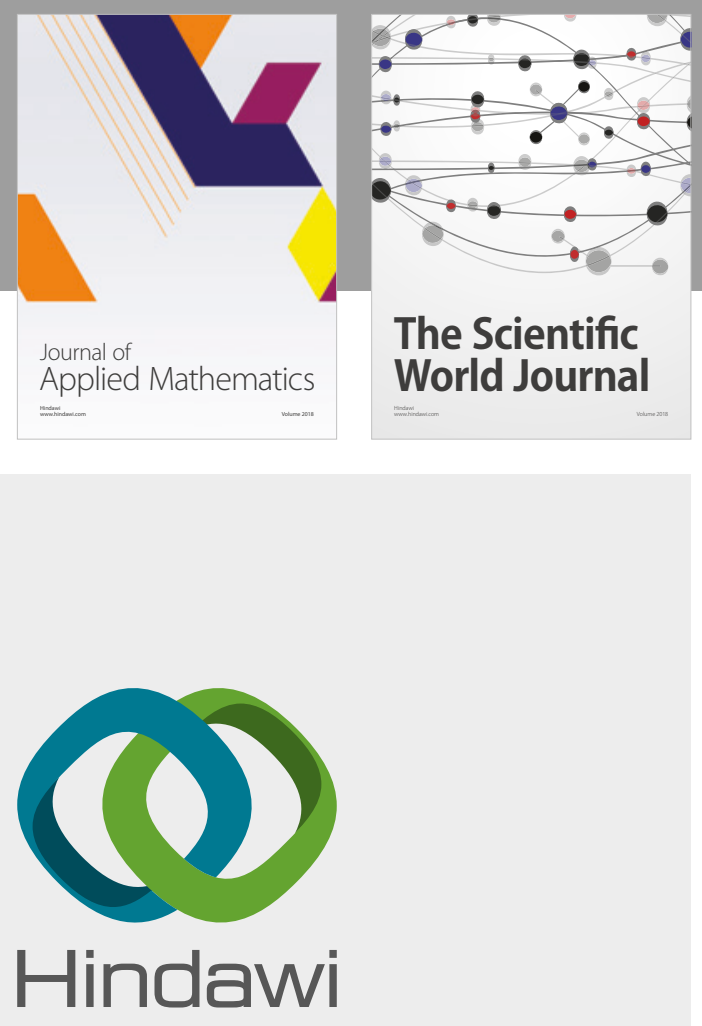

Submit your manuscripts at

www.hindawi.com

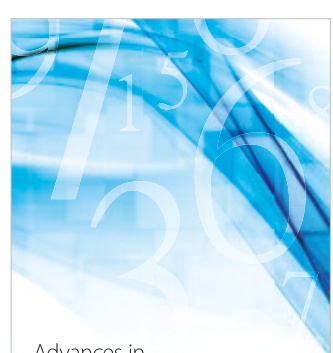

Advances in
Numerical Analysis
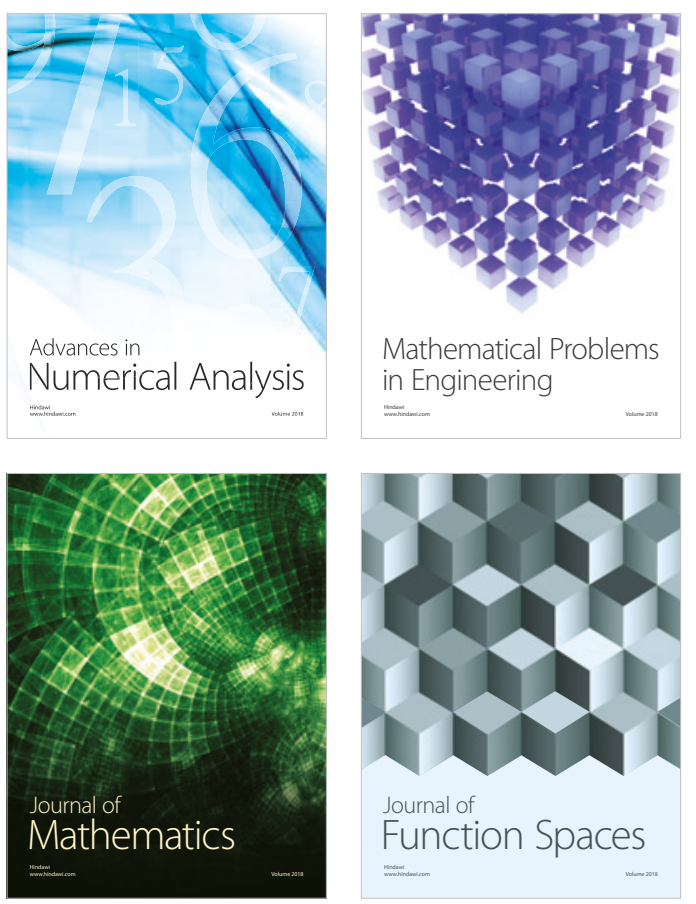

Mathematical Problems in Engineering

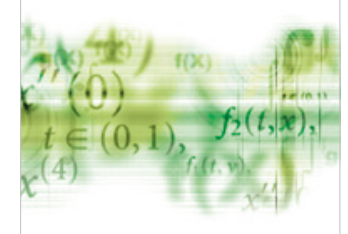

International Journal of

Differential Equations

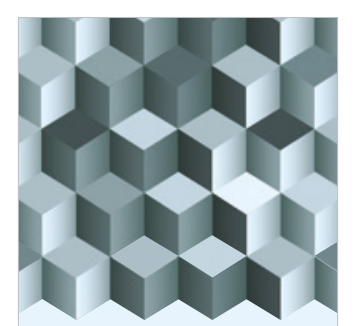

Journal of

Function Spaces

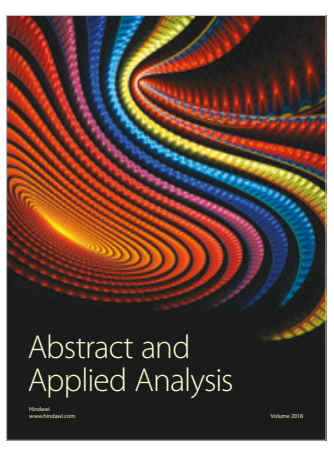

The Scientific

World Journal

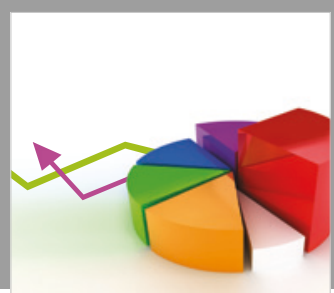

Journal of

Probability and Statistics
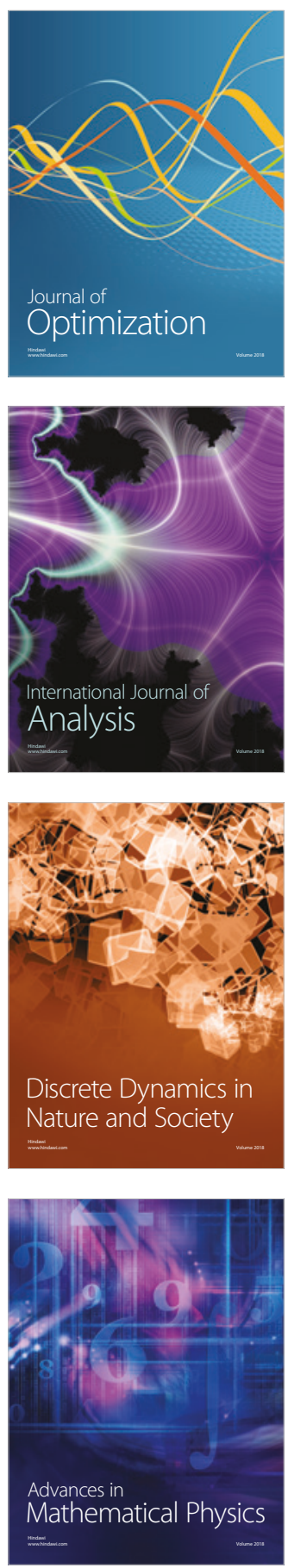